\title{
System performance and economic analysis of solar-assisted cooling/heating system
}

\author{
B.J. Huang ${ }^{\mathrm{a}, *}$, J.H. Wu ${ }^{\mathrm{a}}$, R.H. Yen ${ }^{\mathrm{a}}$, J.H. Wang ${ }^{\mathrm{a}}$, H.Y. Hsu ${ }^{\mathrm{a}}$, C.J. Hsia ${ }^{\mathrm{a}}$, C.W. Yen ${ }^{\mathrm{a}}$, \\ J.M. Chang ${ }^{\mathrm{b}}$ \\ a Department of Mechanical Engineering, National Taiwan University, Taipei, Taiwan \\ ${ }^{\mathrm{b}}$ Department of Refrigeration, Air Conditioning and Energy Engineering, National Chin-Yi University of Technology, Taichung, Taiwan
}

Received 20 November 2010; received in revised form 2 August 2011; accepted 15 August 2011

Available online 13 September 2011

Communicated by: Associate Editor Yanjun Dai

\begin{abstract}
The long-term system simulation and economic analysis of solar-assisted cooling/heating system (SACH-2) was carried out in order to find an economical design. The solar heat driven ejector cooling system (ECS) is used to provide part of the cooling load to reduce the energy consumption of the air conditioner installed as the base-load cooler. A standard SACH-2 system for cooling load $3.5 \mathrm{~kW}(1 \mathrm{RT})$ and daily cooling time $10 \mathrm{~h}$ is used for case study. The cooling performance is assumed only in summer seasons from May to October. In winter season from November to April, only heat is supplied. Two installation locations (Taipei and Tainan) were examined.

It was found from the cooling performance simulation that in order to save $50 \%$ energy of the air conditioner, the required solar collector area is $40 \mathrm{~m}^{2}$ in Taipei and $31 \mathrm{~m}^{2}$ in Tainan, for $\mathrm{COP}_{j}=0.2$. If the solar collector area is designed as $20 \mathrm{~m}^{2}$, the solar ejector cooling system will supply about $17-26 \%$ cooling load in Taipei in summer season and about $21-27 \%$ cooling load in Tainan. Simulation for long-term performance including cooling in summer (May-October) and hot water supply in winter (November-April) was carried out to determine the monthly-average energy savings. The corresponding daily hot water supply (with $40{ }^{\circ} \mathrm{C}$ temperature rise of water) for $20 \mathrm{~m}^{2}$ solar collector area is 616-858 L/day in Tainan and 304-533 L/day in Taipei.

The economic analysis shows that the payback time of SACH-2 decreases with increasing cooling capacity. The payback time is 4.8 years in Tainan and 6.2 years in Taipei when the cooling capacity $>10$ RT. If the ECS is treated as an additional device used as a protective equipment to avoid overheating of solar collectors and to convert the excess solar heat in summer into cooling to reduce the energy consumption of air conditioner, the payback time is less than 3 years for cooling capacity larger than 3 RT.
\end{abstract}

(c) 2011 Elsevier Ltd. All rights reserved.

Keywords: Ejector cooling; Solar ejector cooling; Economic analysis of solar cooling

\section{Introduction}

The ejector cooling system (ECS) using low boiling point refrigerant is suitable for solar cooling application due to its simple design and low cost. Huang et al. (1998, 1999) has shown that the COP of an ECS using R141b, with a proper design of ejector and system structure, can reach 0.54 at generator temperature $84^{\circ} \mathrm{C}$, condenser

\footnotetext{
* Corresponding author.

E-mail address: bjhuang@seed.net.tw (B.J. Huang).
}

temperature $28^{\circ} \mathrm{C}$, and evaporator temperature $8^{\circ} \mathrm{C}$. This makes the ECS become competitive to the sorption (absorption or adsorption) system that is much more complicated in design and more expensive (Arbel and Sokolov, 2004; Nguyen et al., 2001; Sokolov and Hershgal, 1990a, b, 1991; Sun, 1997).

If the ECS was driven by solar energy, it always requires a back-up system to make up the heat to keep a constant cooling capacity for space cooling during cloudy or rainy periods (Fig. 1). Heat supplied by fossil fuel or electricity was generally adopted. This however causes a problem of 


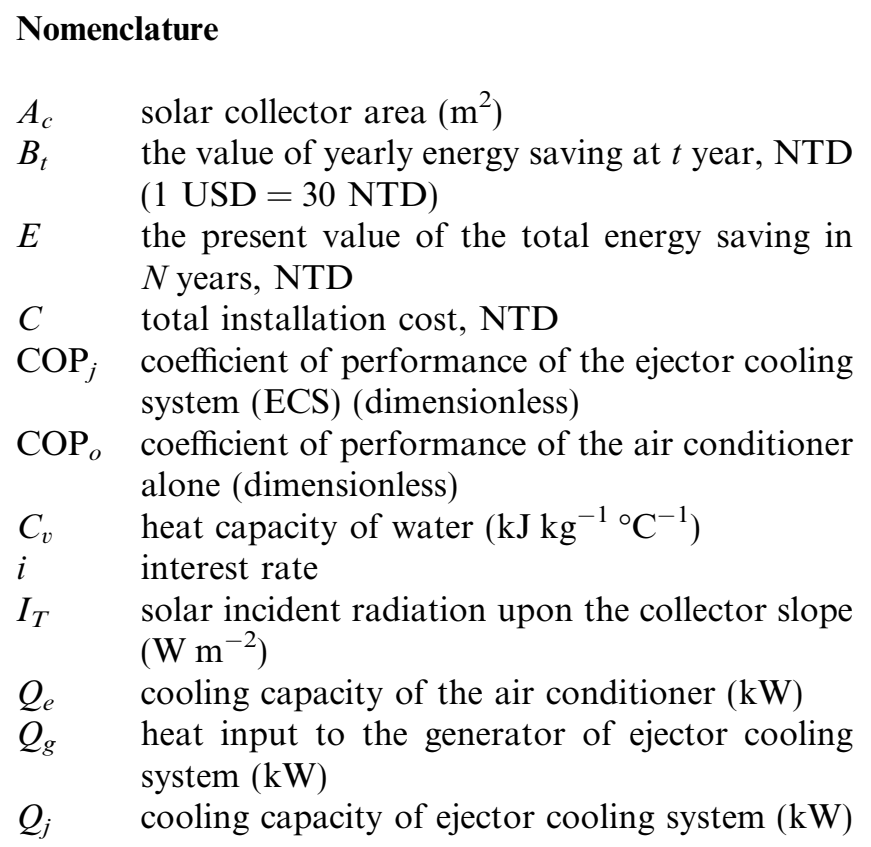

$Q_{j \max }$ designed maximum cooling capacity of ECS $(\mathrm{kW})$

$Q_{\text {load }} \quad$ designed cooling load of the cooling space $(\mathrm{kW})$

$r_{\text {loss }} \quad Q_{j} / Q_{\text {load }}$, fraction of system heat loss (dimensionless)

$t_{i} \quad$ initial time of daily solar heating process (h)

$t_{f} \quad$ final time of daily solar heating process (h)

$V_{w} \quad$ daily hot water supply at $\Delta T_{w}\left(\mathrm{~L} \mathrm{day}^{-1}\right)$

$W_{c o} \quad$ input power of air conditioner alone $(\mathrm{kW})$

$W_{c 2}$ input power of air conditioner in SACH-2 $(\mathrm{kW})$

$\Delta W_{c 2} \quad W_{c o}-W_{c 2}$, energy saving of SACH-2 in cooling performance $(\mathrm{kW})$

$\Delta T_{w} \quad$ water temperature rise in heating performance of $\mathrm{SACH}-2\left({ }^{\circ} \mathrm{C}\right)$

$\rho_{w} \quad$ water density $\left(\mathrm{kg} \mathrm{m}^{-3}\right)$

$\eta \quad$ solar collector efficiency additional investment of heaters and low efficiency in heat supply.

Another problem has been noted recently that a solar heating system installed essentially for space heating in winter seasons will produce too much heat in summer while cooling is required. ECS can thus provide a promising solution to convert the excess heat into cooling in summer.

Huang et al. (2010) proposed a solar-assisted heating/ cooling system $(\mathrm{SACH})$ to cope with the above problems. The solar ejector cooling system is used as the boosting cooling device to provide part of the cooling load to reduce the energy consumption of the air conditioner.

The solar-assisted ejector cooling/heating system (SACH-2) was studied in the present research, in which a conventional inverter-type air conditioner (heat pump) made of variable-speed compressor are connected in parallel with a solar ejector cooling system as shown in Fig. 2. When solar irradiation is high enough to drive ECS, the cooling load is directly supplied by the ECS and the energy consumption of the compressor can be reduced by regulating the rotational speed of the inverter-type air conditioner.
During cloudy or rainy periods or at night, SACH-2 will provide the entire cooling load from the inverter-type air conditioner (heat pump) as usual. SACH-2 can also produce hot water from the solar collector.

Extensive research on the engineering design, optimal control, and performance test of SACH-2 was carried out by Huang et al. (2010). Since ejector is a simple device which can be easily and cheaply manufactured, it seems that the solar ejector cooling system can be competitive to other solar cooling technologies such as absorption or adsorption systems. However, the coefficient of performance (COP) of ejector cooling system is still not very high. So, there may be an optimal system design of SACH-2 which is most economical. The present research continues to study this problem through the system simulation and economic analysis.

\section{Analytical model}

The system performance of SACH-2 can be carried out from the input of solar radiation data and given design parameters of SACH-2. The long-term system performance

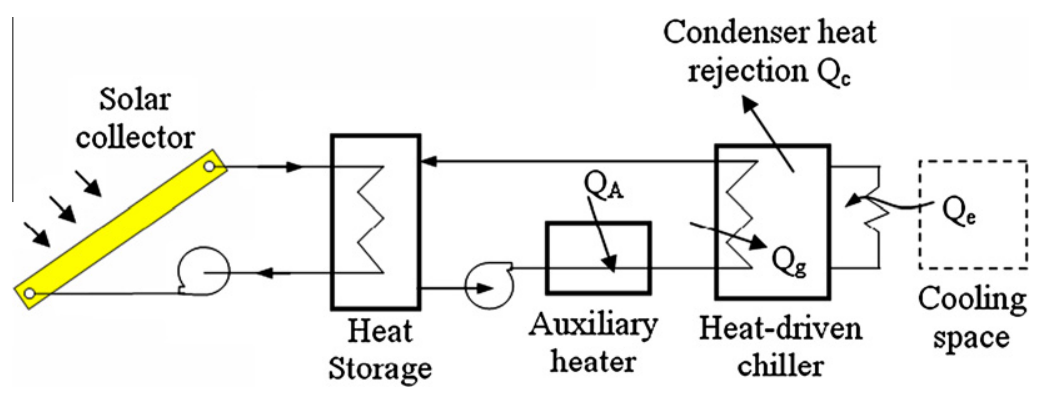

Fig. 1. Conventional solar cooling system. 


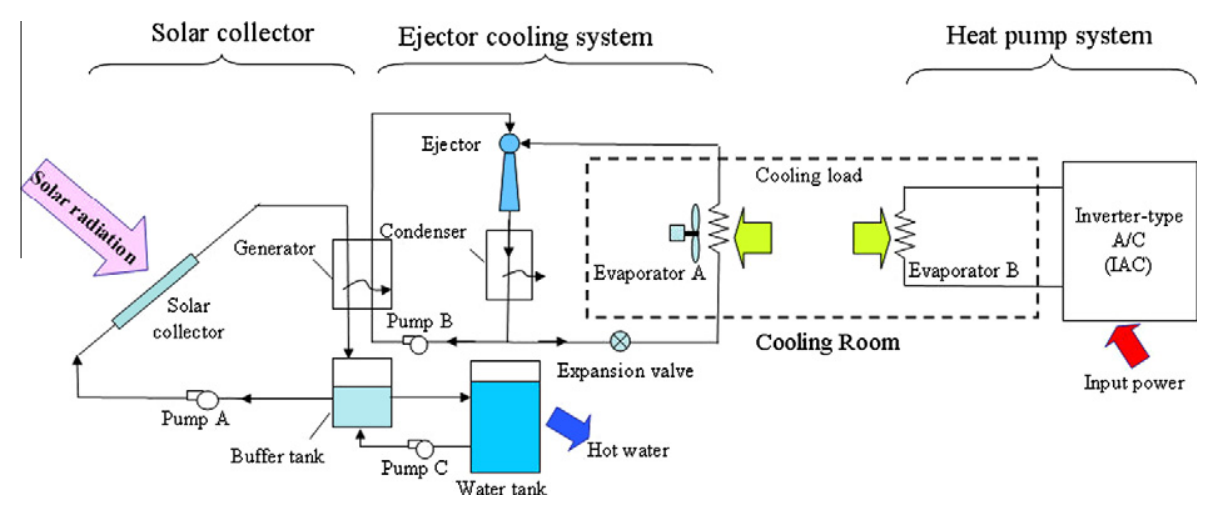

Fig. 2. Solar-assisted cooling/heating system in parallel configuration (SACH-2).

can be simulated using a physical model derived from the principle of energy balance.

\subsection{Physical model of $\mathrm{SACH}-2$}

SACH-2 is designed in parallel configuration as shown in Fig. 2. The solar ejector cooling system (ECS) is connected in parallel with an inverter-type air conditioner (heat pump). From the conservation of energy, the instantaneous energy collected by the solar heating system can be expressed as the following equation:

$Q_{g}(t)=I_{T}(t) \times A_{c} \times \eta \times\left(1-r_{\text {loss }}\right)$

where $I_{T}$ is the solar incident radiation upon the collector slope, $A_{c}$ is total absorbing area, $\eta$ is the collector efficiency, $r_{\text {loss }}$ is the fraction of system heat loss.

Applying energy balance to the ejector cooling system, we obtain the cooling capacity supplied by the ejector cooling system, $Q_{j}$, as the following equation

$Q_{j}=Q_{g} \times \mathrm{COP}_{j}$

where $\mathrm{COP}_{j}$ is the coefficient of performance of the ejector cooling system (ECS). $\mathrm{COP}_{j}$ is among $0.2-0.5$ for SACH-2 which operates independently.

For air conditioning, the fraction of cooling capacity supplied by $\mathrm{SACH}-2$ is

$r_{c}=Q_{j} / Q_{\text {load }}$

For SACH-2, the designed maximum cooling capacity of ECS, $Q_{\text {jmax }}$, should be equal to the designed cooling load of the cooling space $Q_{\text {load }}$. The input power of air conditioner alone is

$W_{c o}=\frac{Q_{e}}{\operatorname{COP}_{o}}$

where $Q_{e}$ is the cooling capacity of the air conditioner and $\mathrm{COP}_{o}$ is the coefficient of performance of the air conditioner alone. The input power of air conditioner in $\mathrm{SACH}-2$ is

$W_{c 2}=\frac{\left(1-r_{c}\right) Q_{e}}{\operatorname{COP}_{o}}$

The energy saving of SACH-2 in cooling performance is
$\Delta W_{c 2}=W_{c o}-W_{c 2}$

SACH-2 will also supply heat simultaneously. The heating load depends on seasons. In winter, the solar energy collected $Q_{g}$ will be used to supply heat for a building. For hot water supply, the amount of daily hot water supply at $40{ }^{\circ} \mathrm{C}$ temperature rise $\left(\Delta T_{w}\right)$ is

$V_{w}=\frac{\int_{t_{i}}^{t_{f}} I_{T}(t) A_{c} \eta\left(1-r_{\text {loss }}\right) d t}{\rho_{w} C_{v} \Delta T_{w}}, \mathrm{~L} /$ day

Fig. 3 is the analytical procedure of SACH-2 system performance. For given instantaneous solar radiation data $I$ which is obtained from long-term hourly meteorological record by local weather stations, the solar irradiation on tilted collector surface $I_{T}$ can be converted. The total energy saving of SACH-2 can be calculated by integrating the hourly performance.

A computer simulation program was developed in the present study for the thermal performance simulation of $\mathrm{SACH}-2$ with various system design parameters.

\subsection{Meteorological data processing}

In the present study, we adopt the hourly meteorological data recorded in local weather station of Taipei (northern Taiwan) and Tainan (southern Taiwan) from 2003 to 2008. Fig. 4 is the monthly-average daily total horizontal solar irradiation for every month. Fig. 5 is the daily total horizontal solar irradiation. It is seen that the solar irradiation in Tainan is about $27 \%$ higher than Taipei.

\section{Results of system performance analysis}

\subsection{Cooling performance simulation results of $\mathrm{SACH}-2$}

SACH-2 is designed in parallel configuration as shown in Fig. 2. The solar collector efficiency $\eta$ is taken as 0.615 at temperature $100{ }^{\circ} \mathrm{C}$ for a commercial high-performance vacuum-tube collector. The fraction of system heat loss $r_{\text {loss }}$ is taken as 0.2 .

The system performance of SACH can be simulated for a specific system design. For easy understanding, a standard SACH design which is suitable for an ordinary family 


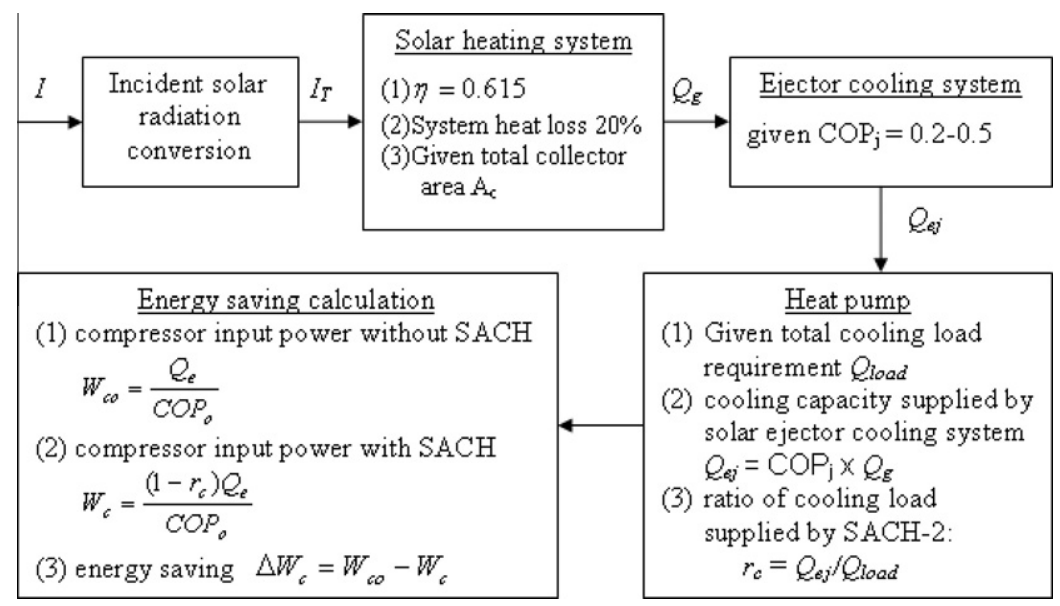

Fig. 3. Analytical procedure of SACH-2 system performance.

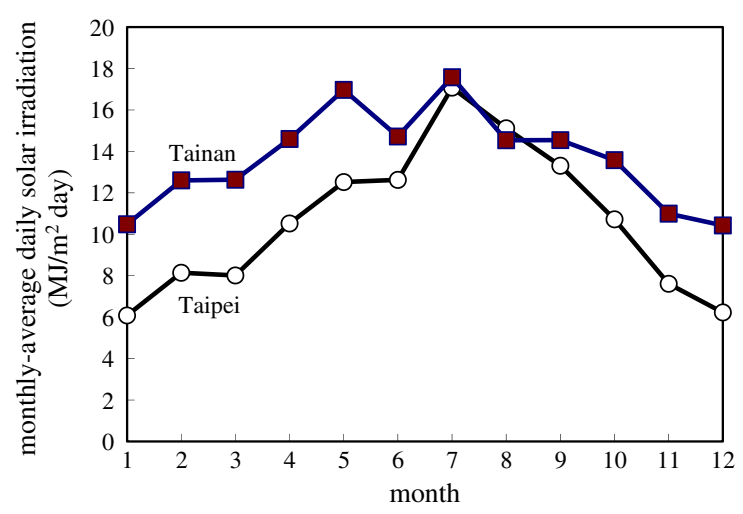

Fig. 4. Monthly-average daily total horizontal solar irradiation.

or a small office space with floor area $30-50 \mathrm{~m}^{2}$ is taken in the present study with the following conditions:

- cooling load: $3.5 \mathrm{~kW}$ (1 RT)

- daily operation time for cooling: $10 \mathrm{~h}$
- total daily cooling load: $35 \mathrm{~kW} \mathrm{~h}(10 \mathrm{RT} \mathrm{h})$.

The design of solar collector area depends on the meteorological data, the fraction of solar energy contribution, and the cooling load etc. Since solar cooling from SACH-2 is provided only in summer season from May to October, the month having the lowest solar irradiation was selected as the design baseline or lower bound. That is October as seen from Fig. 4. This can give a quick answer of the required solar collector area for a given performance $\left(\mathrm{COP}_{j}\right)$ of ECS.

Figs. 6 and 7 shows the variation of daily cooling capacity supply by ECS with the installed collector area in Taipei and Tainan, respectively. Since the cooling load is set as $1 \mathrm{RT}$ for operating time $10 \mathrm{~h} /$ day, i.e. total daily cooling energy is $10 \mathrm{RT} \mathrm{h} /$ day, $100 \%$ cooling load is supplied by solar ECS and there is no power consumption of the air conditioner. For $5 \mathrm{RT}$ h/day cooling energy it means that $50 \%$ cooling load is supplied by solar ECS and 50\% power consumption of the air conditioner is saved. It is seen that for $50 \%$ energy saving of the air conditioner, the required

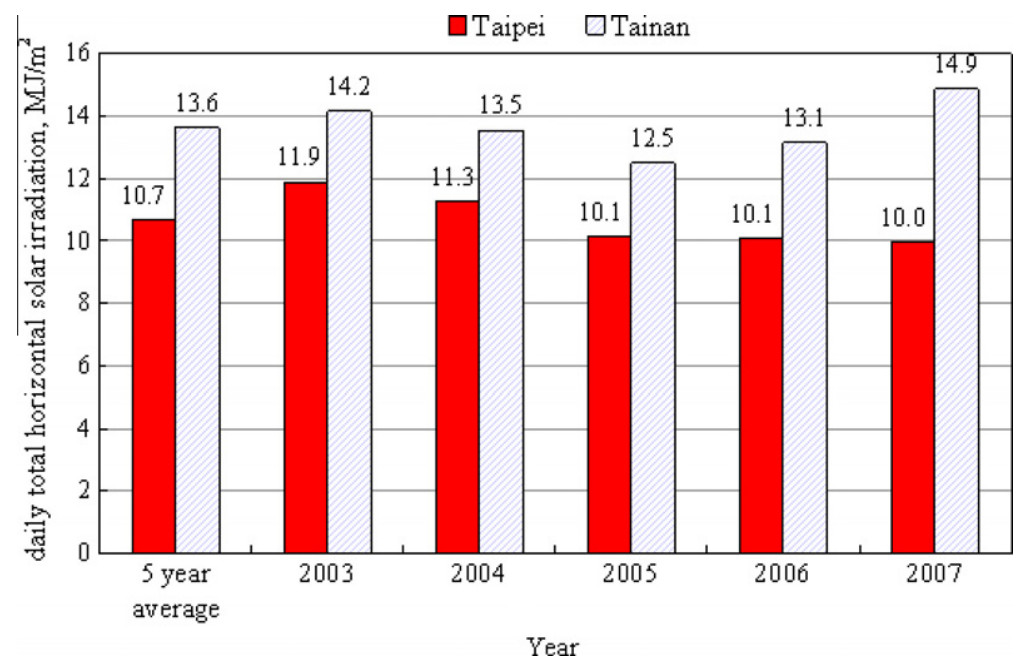

Fig. 5. Yearly-average daily total horizontal solar irradiation. 


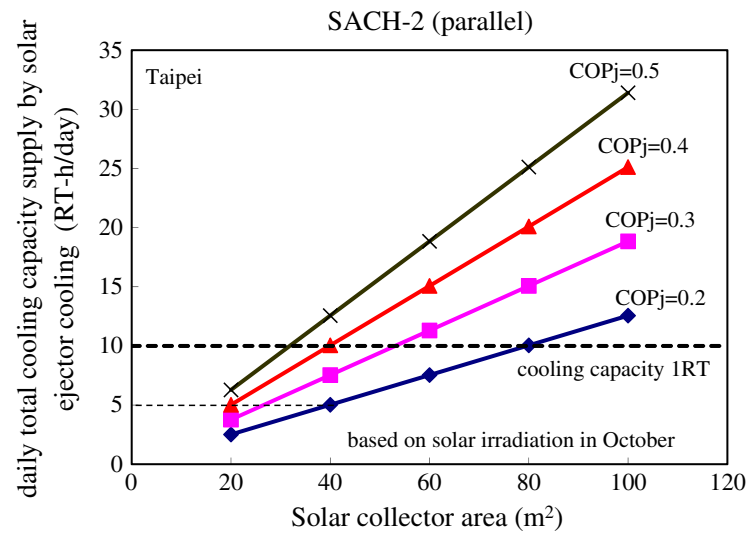

Fig. 6. Daily cooling capacity supplied by ECS (Taipei).

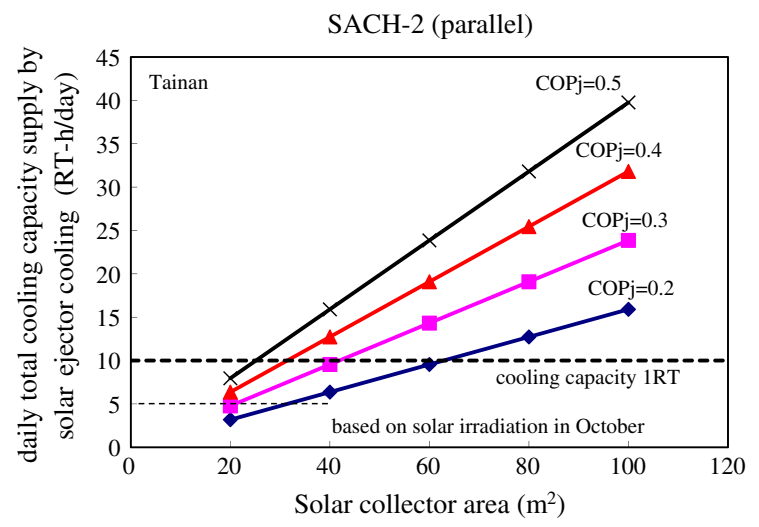

Fig. 7. Daily ejector cooling capacity supply (Tainan).

solar collector area is $40 \mathrm{~m}^{2}$ in Taipei, and $31 \mathrm{~m}^{2}$ in Tainan, for $\mathrm{COP}_{j}=0.2$ which can be easily achieved using the present technology of ECS (Huang et al., 1998, 1999).

To see how much solar ejector cooling can contribute the cooling load (1 RT), we further assume that the solar collector area is $20 \mathrm{~m}^{2}$ which can be easily installed in most houses and run the simulation for $\mathrm{COP}_{j}=0.2$, the conservative value. Fig. 8 indicates that for solar collector area $20 \mathrm{~m}^{2}$, the solar ejector cooling system will supply about $17-26 \%$ cooling load $r_{c}$ (i.e. saving $17-26 \%$ energy of the air conditioner, from Eq. (3)) in Taipei in summer season. For the same solar collector area $20 \mathrm{~m}^{2}$, the solar ejector cooling system will supply about $21-27 \%$ cooling load (i.e. saving $21-27 \%$ energy of the air conditioner) in Tainan (Fig. 9). The energy saving is linearly proportional to the solar collector area and $\mathrm{COP}_{j}$ of the ECS. The above results can be used to calculate the energy saving of a SACH-2 with different collector area and $\mathrm{COP}_{j}$ by multiplying the ratio of the real collector area with respect to the reference value $\left(20 \mathrm{~m}^{2}\right)$ or the ratio of real $\mathrm{COP}_{j}$ with respect to the reference value $(0.2)$.

\subsection{Overall cooling and heating performance of $S A C H-2$}

Assume that the solar collector area is $20 \mathrm{~m}^{2}$. Simulation for long-term performance from 2003 to 2008 including

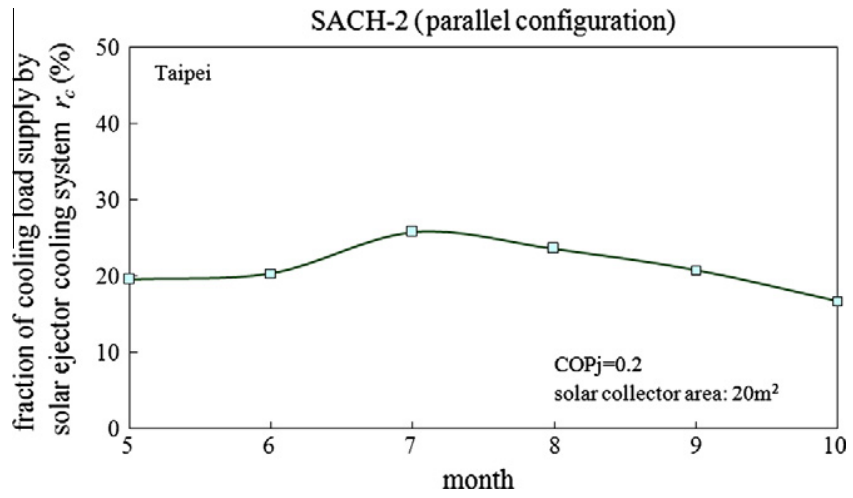

Fig. 8. Fraction of cooling load supplied by solar ECS (Taipei).

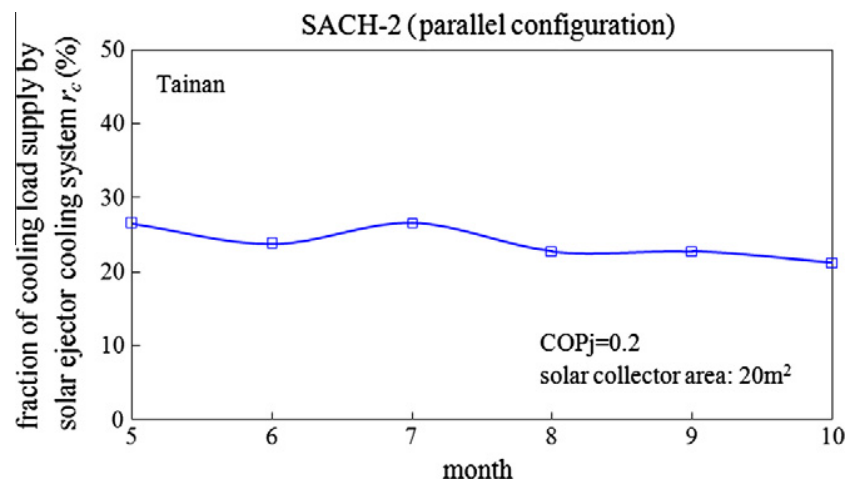

Fig. 9. Fraction of cooling load supplied by solar ECS (Tainan).

cooling in summer (May-October) and heating in winter (November-April) was carried out for SACH-2 in Taipei and Tainan. $\mathrm{COP}_{j}$ of ECS is still taken as 0.2 for SACH2. The monthly average energy savings are shown in Fig. 10. The energy saving is linearly proportional to the solar collector area and the $\mathrm{COP}_{j}$ of the ECS. The results of Fig. 10 thus can be used to calculate the energy saving of a SACH with different collector area and $\mathrm{COP}_{j}$ by multiplying the ratio of the real collector area with respect to the reference value $\left(20 \mathrm{~m}^{2}\right)$ or the ratio of real COPj with respect to the reference value $(0.2)$.

SACH-2 will supply hot water in winter season to save the heating energy as shown in Fig. 10. Table 1 shows the corresponding daily hot water supply (with $40{ }^{\circ} \mathrm{C}$ temperature rise of water) for the $20 \mathrm{~m}^{2}$ solar collector. It is seen that SACH-2 can supply daily hot water 616-858 L/day in Tainan and 304-533 L/day in Taipei. This can satisfy the requirement of about 12-16 residents (average hot water consumption $50 \mathrm{~L} /$ day per person) in Tainan, and 6-10 residents in Taipei.

\section{Economic analysis of SACH-2}

The long-term performance and energy saving of SACH-2 for various designs has been analyzed previously. Based on these simulation results, the economic analysis can be carried out in order to answer the question: what 


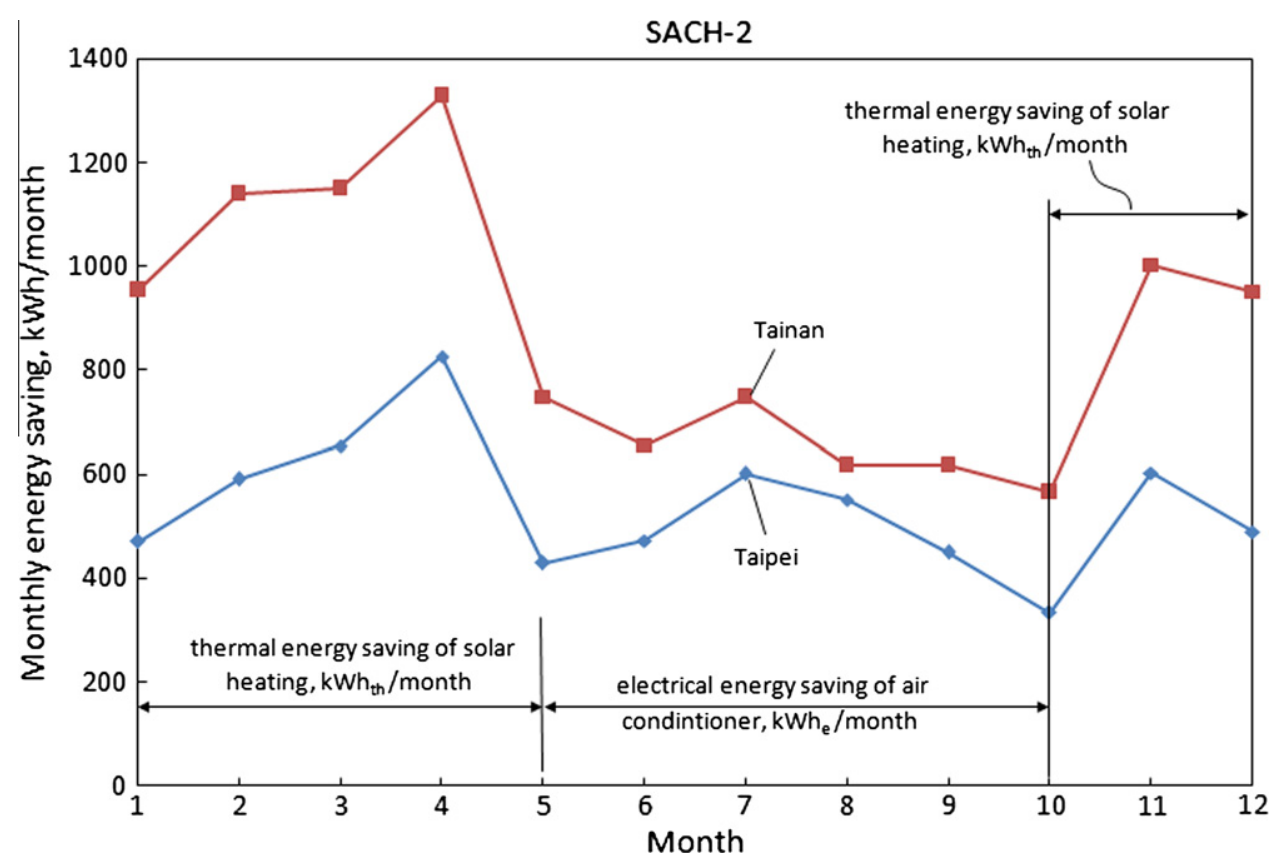

Fig. 10. Performance of SACH-2.

Table 1

Daily hot water supply in winter season for collector area $20 \mathrm{~m}^{2}$.

\begin{tabular}{lll}
\hline \multirow{2}{*}{ Month } & \multicolumn{3}{l}{ Hot water supply $@ 40{ }^{\circ} \mathrm{C}$ rise $(\mathrm{L} /$ day $)$} \\
\cline { 2 - 3 } 1 & Tainan & Taipei \\
\hline 2 & 616 & 304 \\
3 & 736 & 382 \\
4 & 743 & 422 \\
11 & 858 & 533 \\
12 & 646 & 389 \\
\hline
\end{tabular}

is the proper size (cooling capacity) of ECS in the design of $\mathrm{SACH}-2$.

\subsection{Net present value and installation cost of SACH-2}

The method of Net Present Value (NPV) is used in the present study. Eq. (8) is the formula to calculate the NPV where $E$ is the present value of the total energy saving in $N$ years as expressed in Eq. (9), $C$ is the total installation cost and $i$ is the interest rate which is taken as $2.1 \%$.

$N P V=E-C$

$E=\sum_{t=1}^{N} \frac{B_{t}}{(1+i)^{t}}$

where $B_{t}$ is the value of yearly energy saving at $t$ year. The NPV is calculated for $N=20$ years.

The electricity price adopted in the present analysis is based on Taiwan system which charges electricity in low season (November-April) at NTD $3.97 / \mathrm{kW}$ h for monthly total power consumption $>700 \mathrm{kWh} /$ month and NTD $3.55 / \mathrm{kW} \mathrm{h}$ for $<700 \mathrm{~kW} \mathrm{~h} /$ month. [30 NTD $=1 \mathrm{USD}$ ].
For high season (May-October), the electricity price is NTD $5.1 / \mathrm{kW} \mathrm{h}$ for monthly total power consumption $>700 \mathrm{~kW} \mathrm{~h} /$ month and NTD $4.51 / \mathrm{kW} \mathrm{h}$ for $<700 \mathrm{~kW} \mathrm{~h} /$ month.

We assume that $\mathrm{COP}_{j}=0.3$ which is achievable for an ECS based on the state-of-the-art technology (Petrenko and Huang, 2010). Table 2 shows the mass production price estimation of $1 \mathrm{RT}(3.5 \mathrm{~kW})$ ejector cooling system only. For ECS lager than $1 \mathrm{RT}$, the cost increase will be about NTD 20,000 per RT. Table 3 shows the price estimation of ejector cooling system from 1-10 RT.

For SACH-2, the designed cooling capacity of ECS, $Q_{\text {jmax }}$, should be equal to the cooling load of the cooling space $Q_{\text {load }}$. Similar to the simulation process of SACH-2 shown in Fig. 3, for a given cooling load $Q_{\text {load }}$ and $\mathrm{COP}_{j}$, the required solar collector area can be calculated.

The installation cost of solar heating system includes solar collector modules which is NTD $10,000 \mathrm{~m}^{2}$ and auxiliary equipments (piping and insulation, storage tank and

Table 2

Price estimation of $1 \mathrm{RT}$ ejector cooling system.

\begin{tabular}{lc}
\hline Item & NTD $(1$ USD $=30$ NTD $)$ \\
\hline Ejector & 10,000 \\
Condenser & 10,000 \\
Evaporator & 10,000 \\
Generator & 25,000 \\
Refrigerant pump & 15,000 \\
Receiver & 7000 \\
Piping & 6000 \\
Cooling tower & 8000 \\
Control system & 15,000 \\
Frame & 9700 \\
Total & 115,700 \\
\hline
\end{tabular}


Table 3

Price estimation of ejector cooling system of various capacity.

\begin{tabular}{ll}
\hline Ejector cooling system size (RT) & Price (NTD) 1 USD $=30$ NTD \\
\hline 1 & 115,700 \\
2 & 135,700 \\
3 & 155,700 \\
4 & 175,700 \\
5 & 195,700 \\
6 & 215,700 \\
7 & 235,700 \\
8 & 255,700 \\
9 & 275,700 \\
10 & 295,700 \\
\hline
\end{tabular}

pump, installation labor, control systems) which is NTD 380,000 per RT of ECS. From manufacturer, there is 5\% discount per increase of $42 \mathrm{~m}^{2}$ solar collector area and $6 \%$ discount in auxiliary equipment per increase of $42 \mathrm{~m}^{2}$ solar collector area. Fig. 11 shows the total solar heating system installation cost.

Fig. 12 is the variation of total SACH-2 system installation cost with the ejector cooling capacity (or the space cooling load) which is the summation of the ejector cooling system cost and the solar heating system cost. The cost of the existing air conditioner is not included since it is the common equipment.

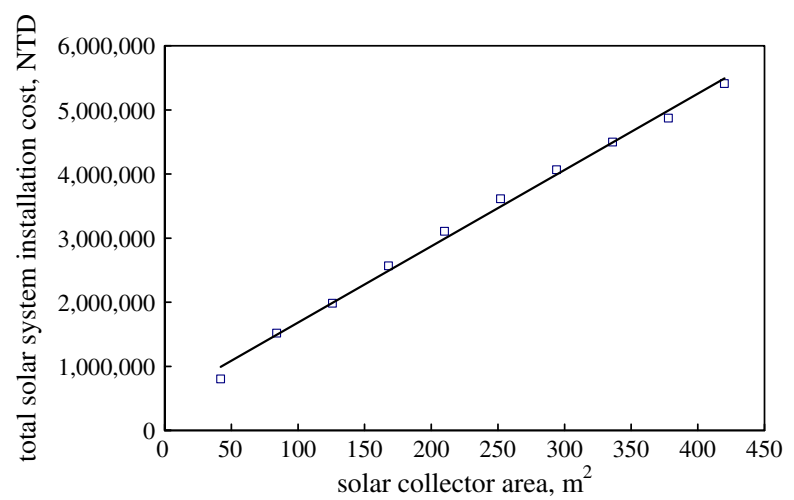

Fig. 11. Total solar heating system installation cost.

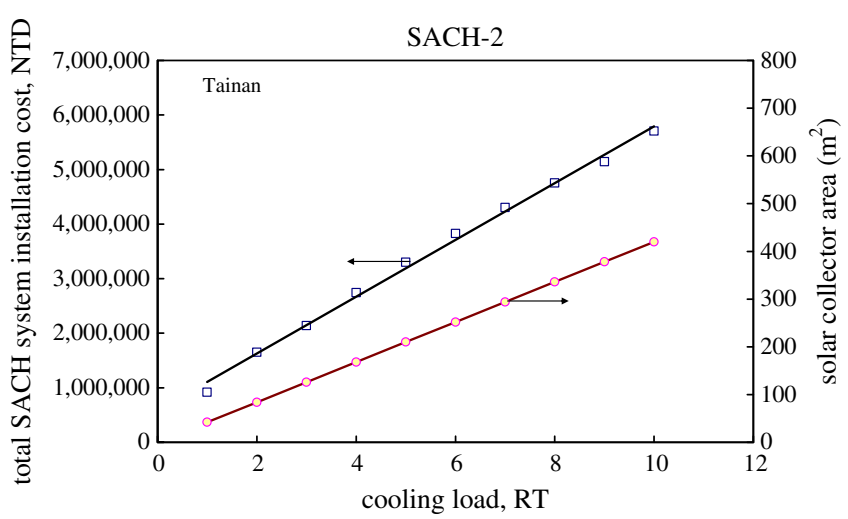

Fig. 12. Total SACH-2 system installation cost.

\subsection{Economic analysis of SACH-2 for cooling and heating}

The NPV of the SACH-2 for $N=20$ years can be calculated using the yearly total energy saving (including cooling and heating) and the electricity price using Eq. (8). Assume that the thermal energy saving in heating from SACH-2 is to replace the electricity consumption since electric heaters are widely used for hot water supply. Fig. 13 shows the total NPV of SACH-2 for 20 year. It is seen that the higher installed capacity, the larger the NPV.

The payback time of SACH-2 can be calculated from Eq. (8) by determining $N_{P B}$ at $\mathrm{NPV}=0$, i.e.

$E=\sum_{t=1}^{N_{P B}} \frac{B_{t}}{(1+i)^{t}}=C$

Fig. 14 shows that the payback time of SACH-2 decreases with increasing cooling capacity and approaches a constant. In Tainan, the payback time is 4.8 years when the cooling capacity $>10 \mathrm{RT}$. In Taipei, the payback time is 6.2 years when the cooling capacity $>10 \mathrm{RT}$.

\subsection{Economic analysis of SACH-2 for cooling only}

In some cold regions, many large solar heating systems are installed for house heating purpose. But there is serious problem of overheating in summer season due very low heating load. The ECS can be used to protect the solar heating system in summer. Therefore, the ECS can be treated as an additional device in SACH-2 used to convert the excess solar heat in summer into cooling to reduce the energy consumption of air conditioner. Only the installation cost of ECS needs to be considered. The NPV is lower as shown in Fig. 15, but the payback time of the ECS is less than 3 years for cooling capacity larger than $3 \mathrm{RT}$ as shown in Fig. 16.

\section{Discussion and conclusion}

The present research develops a system analysis model of SACH-2 and a computer simulation program to analyze the system performance and economic effectiveness of

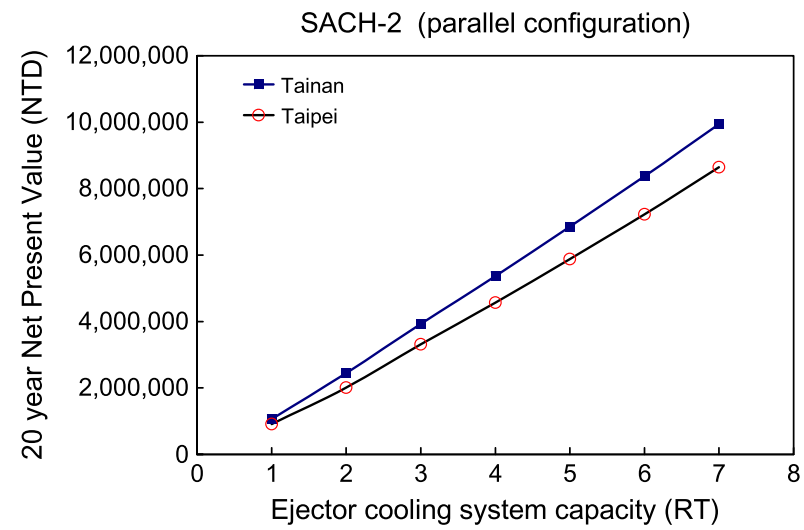

Fig. 13. Total NPV of SACH-2 for 20 year. 


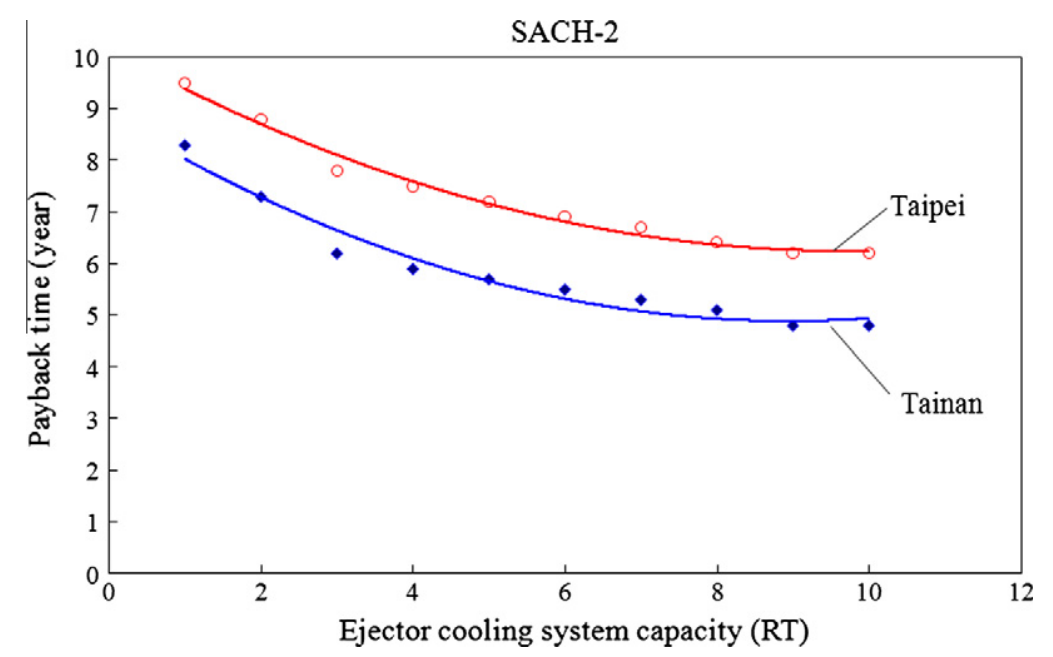

Fig. 14. Payback time of SACH-2.

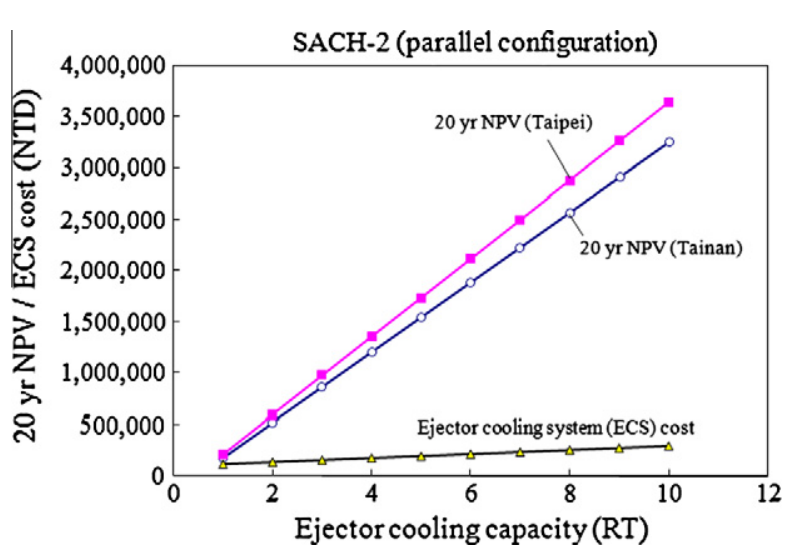

Fig. 15. NPV of SACH-2 for 20 year used in summer cooling only.

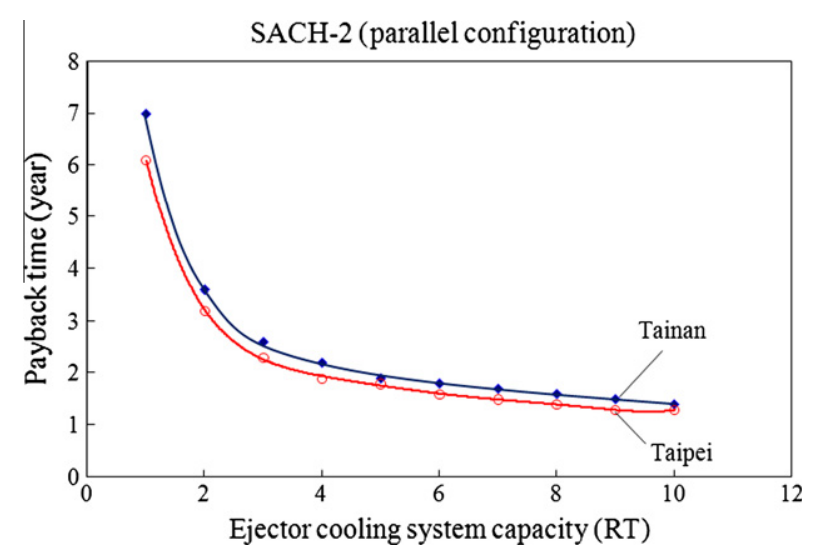

Fig. 16. Payback time of SACH-2 for 20 year used in summer cooling only.

SACH-2 at different designs. A standard design is taken in the present study for the study of system performance of SACH-2 with the following conditions:
- cooling load: $3.5 \mathrm{~kW}$ (1 RT)

- daily operation time for cooling: $10 \mathrm{~h}$

- total daily cooling load: $35 \mathrm{~kW} \mathrm{~h}(10 \mathrm{RT}$ h).

The cooling performance of SACH-2 is assumed only in summer seasons from May to October (6 months a year). In winter season from November to April, only heat is supplied by SACH. Two installation locations (Taipei and Tainan) were studied.

The system simulation for the cooling performance of SACH-2 is used to calculate the required solar collector area. It was found that in order to save $50 \%$ energy of the air conditioner, the required solar collector area is $40 \mathrm{~m}^{2}$ in Taipei and $31 \mathrm{~m}^{2}$ in Tainan, for $\mathrm{COP}_{j}=0.2$ which can be easily achieved using the present technology of ECS. If the solar collector area is designed as $20 \mathrm{~m}^{2}$, the solar ejector cooling system will supply about $17-26 \%$ cooling load (i.e. saving $17-26 \%$ energy of the air conditioner) in Taipei in summer season and about $21-27 \%$ cooling load (i.e. saving $21-27 \%$ energy of the air conditioner) in Tainan. The energy saving is linearly proportional to the solar collector area and the $\mathrm{COP}_{j}$ of the ECS. The results thus can be used to calculate the energy saving of a SACH-2 with different collector area and $\mathrm{COP}_{j}$.

Simulation for long-term performance from 2003 to 2008 including cooling in summer (May-October) and heating in winter (November-April) was carried out for SACH-2 in Taipei and Tainan to determine the monthly-average energy savings. $\mathrm{COP}_{j}$ of ECS is still taken as 0.2 . SACH-2 will supply hot water in winter season to save the heating energy. The corresponding daily hot water supply (with $40{ }^{\circ} \mathrm{C}$ temperature rise of water) for $20 \mathrm{~m}^{2}$ solar collector area is $616-858 \mathrm{~L} /$ day in Tainan and 304-533 L/day in Taipei. This can satisfy the daily requirement of about 12-16 residents (average hot water consumption $50 \mathrm{~L} /$ day per person) in Tainan, and 6-10 residents in Taipei. The energy saving of cooling and heating is linearly proportional to the solar collector area 
and the $\mathrm{COP}_{j}$ of the ECS. The results can be used to calculate the energy saving of a SACH-2 with different collector area and $\mathrm{COP}_{j}$.

The economic analysis shows that the higher installed capacity, the larger NPV. The payback time of SACH-2 decreases with increasing cooling capacity and approaches a constant. In Tainan, the payback time is 4.8 years when the cooling capacity $>10 \mathrm{RT}$. In Taipei, the payback time is 6.2 years when the cooling capacity $>10 \mathrm{RT}$.

In some cold regions, many large solar heating systems are installed for house heating purpose. But there is serious problem of overheating in summer season due to very low heating load. The ECS can be used to protect the solar heating system in summer by consuming the solar heat and converting it into cooling. Therefore, the ECS can be treated as an additional device in SACH-2 used to convert the excess solar heat in summer into cooling to reduce the energy consumption of air conditioner. Only the installation cost of ECS needs to be considered. In this case, the payback time of the ECS is less than 3 years for cooling capacity larger than $3 \mathrm{RT}$.

The system simulation and economic analysis of SACH2 takes a conservative estimation using $\mathrm{COP}_{j}=0.2$. Actually, the $\mathrm{COP}_{\mathrm{j}}$ can be further improved to be higher than 0.4 if the system design of SACH-2 is improved. The system performance can be improved by raising the evaporator temperature of the ECS, or using an advanced control technology (Huang et al., 2010). The present results can be treated as a lower bound of the system performance.

Although the $\mathrm{COP}_{j}$ of the ECS is relatively low as compared with that of absorption systems, the manufacturing cost of ECS is low, especially for small-size machine $(<10 \mathrm{RT})$. It seems that SACH-2 is more suitable for small solar cooling systems $(<10 \mathrm{RT})$.

\section{Acknowledgment}

This publication is based on work supported by Award No. KUK-C1-014-12, made by King Abdullah University of Science and Technology (KAUST), Saudi Arabia.

\section{References}

Arbel, A., Sokolov, M., 2004. Revisiting solar-powered ejector air conditioner-the greener the better. Solar Energy 77, 57-66.

Huang, B.J., Chang, J.M., Petrenko, V.A., Zhuk, K.B., 1998. A solar ejector cooling system using refrigerant R141b. Solar Energy 64 (4-6), 223-226.

Huang, B.J., Chang, J.M., Wang, C.P., Petrenko, V.A., 1999. A 1D analysis of ejector performance. International Journal of. Refrigeration 22, 354-364.

Huang, B.J., Yen, C.W., Wu, J.H., Liu, J.H., Hsu, H.Y., Petrenko, V.O., Chang, J.M., Lu, C.W., 2010. Optimal control and performance test of solar-assisted cooling system. Applied Thermal Engineering 30, 2243 2252.

Nguyen, V.M., Riffat, S.B., Doherty, P.S., 2001. Development of a solarpowered passive ejector cooling system. Applied Thermal Engineering 21, 157-168.

Petrenko, V.O., Huang, B.J., 2010. Advanced ejector air conditioners and chillers utilizing solar energy and waste heat, in: International Conference on Engineering Solutions for Sustainable Development, 17-18 April, 2010, American University in Cairo, Cairo, Egypt.

Sokolov, M., Hershgal, D., 1990a. Enhanced ejector refrigeration cycles powered by low grade heat. Part 1 . Systems characterization. International Journal of. Refrigeration 12, 351-356.

Sokolov, M., Hershgal, D., 1990b. Enhanced ejector refrigeration cycles powered by low grade heat. Part 2. Design procedures. International Journal of. Refrigeration 12, 357-363.

Sokolov, M., Hershgal, D., 1991. Enhanced ejector refrigeration cycles powered by low grade heat. Part 3. Experimental results. International Journal of. Refrigeration 14, 24-31.

Sun, D.W., 1997. Solar powered combined ejector-vapour compression cycle for air conditioning and refrigeration. Energy Conversion and Management 38, 479-491. 